\title{
Environmental Determinants of Bicycling Injuries in Alberta, Canada
}

\author{
Nicole T. R. Romanow, ${ }^{1}$ Amy B. Couperthwaite, ${ }^{2}$ Gavin R. McCormack, ${ }^{3}$ \\ Alberto Nettel-Aguirre, ${ }^{1}$ Brian H. Rowe, ${ }^{2}$ and Brent E. Hagel ${ }^{1}$ \\ ${ }^{1}$ Departments of Paediatrics and Community Health Sciences, Alberta Children's Hospital, University of Calgary, \\ 2888 Shaganappi Trail NW, Calgary, AB, Canada T3B 6A8 \\ ${ }^{2}$ Department of Emergency Medicine and School of Public Health, University of Alberta and 1 G1.50 Walter Mackenzie Centre, \\ 8440-112 Street, Edmonton, AB, Canada T6G 2B7 \\ ${ }^{3}$ Department of Community Health Sciences, University of Calgary, 3rd Floor TRW Building, 3280 Hospital Drive NW, \\ Calgary, AB, Canada T2N $4 Z 6$
}

Correspondence should be addressed to Brent E. Hagel, brent.hagel@albertahealthservices.ca

Received 18 September 2012; Accepted 25 October 2012

Academic Editor: Chris Rissel

Copyright ( 2012 Nicole T. R. Romanow et al. This is an open access article distributed under the Creative Commons Attribution License, which permits unrestricted use, distribution, and reproduction in any medium, provided the original work is properly cited.

This study examined environmental risk factors for bicycling injuries, by combining data on bicyclist injuries collected by interviews in the emergency department (ED) with street-level environmental audits of injury locations, capturing path, roadway, safety, land use, and aesthetic characteristics. Cases were bicyclists struck by a motor vehicle (MV) or with severe injuries (hospitalized). Controls were bicyclists who were not hit by a car or those seen and discharged from the ED, matched on time and day of injury. Logistic regression odds ratios (ORs) adjusted for age, sex, peak time, and bicyclist speed with $95 \%$ confidence intervals (CIs) were estimated to relate injury risk to environmental characteristics. Factors contributing to MV events included greater traffic volume (OR 5.13; 95\% CI [1.44, 18.27]), intersections (OR 6.89; 95\% CI [1.48, 32.14]), retail establishments (OR $5.56 ; 95 \%$ CI $[1.72,17.98])$, and path obstructions (OR 3.83; 95\% CI $[1.03,14.25]$ ). Locations where the road was in good condition (OR 0.25; 95\% CI $[0.07,0.96])$ and where there was high surveillance from surrounding buildings (OR 0.32; 95\% CI $[0.13,0.82])$ were associated with less severe injuries. These findings could be used by bicyclists and transportation planners to improve safety.

\section{Introduction}

Physical activity, such as bicycling, provides health benefits for all ages $[1,2]$. Bicycling can reduce the risk of allcause mortality independent of participation in other types of leisure activity $[1,2]$. Despite its potential to improve health, rates of bicycling vary widely by country and between cities [3-6]. Individual-level characteristics (e.g., gender, age, and income), nonmodifiable factors (e.g., climate and geography), and environmental characteristics, including urban design and safety, contribute to these variations and influence whether people choose to bicycle $[7,8]$.

The inherent injury risks associated with bicycling in part explain why more people do not cycle. Only 1.3\% of Canadians cycled to work in 2006 [9]. Bicycling injuries are common and result in an important number of emergency department (ED) visits and hospitalizations [10-12]. Bicycling injuries involving motor vehicles (MVs) tend to result in severe injuries and may result in death [10]. Personal characteristics including age ( $<6$ years or $>39$ years), sex (males), alcohol use, and high speed are known to be associated with severe bicycling injuries $[10,13,14]$.

To date, the majority of injury risk studies have focused on individual-level risk factors with few taking into consideration upstream determinants of risk such as urban and transportation planning and policy [15]. Creating built environments that are safe and convenient for bicycling as well as other forms of physical activity is an example of an upstream intervention that has the potential to both 
lower the incidence of injuries and increase levels of physical activity at the population level. While there is a plethora of evidence associating built environmental characteristics with physical activity behaviour $[15,16]$, limited evidence on the relationship between built environment and injury exists, especially for injuries involving bicyclists. Nevertheless, the available evidence suggests an increased risk of injury associated with bicycling on the sidewalk compared with bicycling off-road paths or trails $[17,18]$ —a finding which may be due to poor sidewalk maintenance or conflicts with pedestrians. Roundabouts have also been found to be particularly dangerous for bicyclists $[19,20]$, perhaps due to a high number of potential conflict points or driver distraction and other challenges while navigating the roundabout. Apart from these factors, there is a lack of data on built environmental determinants of bicycling injuries. This area of research has been identified as a priority in order to develop effective place-related interventions for activity promotion and injury prevention [8].

The purpose of this study was to examine the built environmental characteristics (e.g., road/path characteristics, natural features, and obstacles) of locations where bicycling injuries occurred in two urban Alberta cities, by combining data on injury circumstances with street-level environmental audits of crash locations. The objectives were to (1) compare the characteristics of locations where bicyclists were struck by a MV with those of locations where bicyclists were injured in non-MV-related incidents and (2) compare the characteristics of severe injury crash locations with those of nonsevere injury locations.

\section{Materials and Methods}

2.1. Study Design and Sample Recruitment. In this casecontrol study, participants were injured bicyclists of all ages who presented to any one of 7 EDs in Calgary (Alberta Children's Hospital, Foothills Medical Centre, Rockyview Hospital, Peter Lougheed Centre) or Edmonton (Stollery Children's Hospital, University of Alberta Hospital, North East Community Health Centre), Alberta, from May to October 2010. These EDs were chosen as they represent all the hospitals in Calgary and a sufficient number of sites in Edmonton to cover a representative catchment area in that city. In addition, the Foothills Medical Centre, Alberta Children's Hospital, University of Alberta Hospital, and Stollery Children's Hospital are designated adult and paediatric regional trauma centres for their respective areas.

Any injured bicyclist who presented to one of the study EDs was eligible. Eligible patients were identified using the Regional Emergency Department Information System and by reviewing ED records daily. Patients were excluded if they did not speak English, were cycling indoors, using a stationary exercise bicycle, were not riding the bicycle (e.g., cleaning or walking with the bike) at the time of the injury, or if they could not provide sufficient details about the crash location for auditors to visit the site. Bicyclists who were injured outside the established city limits of Calgary or Edmonton were also excluded due to feasibility issues in conducting the audits (i.e., distance). Following informed consent, eligible bicyclists were interviewed in the ED using a questionnaire developed for the study. The questionnaire was based on previous work on bicycle and motorcycle injuries $[10,21]$, and was pilot tested with a convenience sample of respondents. If bicyclists were missed in the ED, they were mailed a study information package and contacted by telephone. If they consented, a telephone interview was conducted. Participants were asked questions about the circumstances surrounding their crash, including the location, date, and time. Injury information was extracted from the patients' medical chart.

Two case definitions were used. The first case group included bicyclists injured in a collision with an MV. The second case group included bicyclists whose injuries required admission to a hospital unit after their ED presentation. If a bicyclist had a collision with an MV and was hospitalized, they were included in both case groups. Controls were recruited from the same EDs. A separate control group was selected for each case series. The first control group (for MV cases) was composed of bicyclists injured while riding on the road or the sidewalk but not struck by an MV. Bicyclists riding on the sidewalk were included as potential controls for MV cases because they were exposed to MVs even though they were not riding directly on the road (e.g., when crossing a street). The second control group (for severe cases) included bicyclists with minor injuries, regardless of riding location (e.g., bike paths) or mechanism of injury (MV or other). Cases and controls were individually matched based on time and day of the week, within two weeks prior to or following the case event. Each case was matched to as many as 3 controls; however, MV cases with severe injuries were matched with up to 6 controls ( $3 \mathrm{MV}$ controls and 3 minor injury controls). We combined data on bicyclists' crash circumstances and injuries with information on the environmental characteristics of the crash locations.

\subsection{Environmental Audits of Crash Locations. Street-level} data were collected by auditing crash locations using the Systematic Pedestrian and Cyclist Environment Scan (SPACES), which has been demonstrated to have acceptable levels of interrater reliability [22]. Auditors recorded information for both sides of a street segment. Side 1 was defined as the bicyclist's direction of travel. If the direction of travel was unknown, auditors agreed on which side to record as side 1. In general, the area under observation was approximately equal to one street block; however, this varied depending on the location. An additional audit form (see Supplementary Material, available online at doi:10.1155/2012/487681) was created to record features thought to be related to bicycling that were not captured by the SPACES. Trained research assistants (RAs) visited the locations for each matched set at the same time of day as the case injury event, as soon as possible after the event. When resources permitted, two RAs visited the sites and conducted the audits separately in order to assess interrater reliability. One RA was blinded to the case-control status of the location, and their data were used for the analysis. The environmental features examined 
TABLE 1: Definitions of environmental characteristics assessed in audits of bicycling injury locations.

\begin{tabular}{|c|c|}
\hline Variable & Definition \\
\hline Traffic speed & $\leq 30 \mathrm{~km} / \mathrm{hr}$ versus $>30 \mathrm{~km} / \mathrm{hr}$ estimated average vehicle speed. \\
\hline Traffic volume & $\begin{array}{l}\text { Number of vehicles per hour; } 3 \text { categories: (1) low ( } \leq 250 \text { vehicles/hr); ( } 2) \text { medium } \\
\text { ( } 250-749 \text { vehicles/hr); ( } 3 \text { ) high ( } \geq 750 \text { vehicles/hr). }\end{array}$ \\
\hline Bicyclist volume & No bicyclists observed at location versus at least one bicyclist. \\
\hline Path type & $\begin{array}{l}\text { Sidewalk, multiuse path (shared by bicyclists and pedestrians) with markings (e.g., center } \\
\text { line, stencils), or without markings. }\end{array}$ \\
\hline Path location & $\begin{array}{l}\text { For each side } 3 \text { categories: (1) within } 1 \text { metre of roadway; (2) between } 1 \text { and } 3 \text { metres; ( } 3 \text { ) } \\
>3 \text { metres. }\end{array}$ \\
\hline Path material & For each side, continuous or slab concrete and bitumen (asphalt) versus gravel and grass. \\
\hline Path/road slope & Flat versus moderate or steep slope (for each side of path). \\
\hline Path/road condition & Good versus moderate, poor, or under repair (for each side of path). \\
\hline Path obstructions & $\begin{array}{l}\text { For each side, presence of permanent obstructions (poles, signs, trees, benches, tables, } \\
\text { fences) versus none. }\end{array}$ \\
\hline Bike lane & Marked designated bicycle lane on roadway versus no marked lane. \\
\hline Roadway lanes & $1-3$ lanes versus 4 or more lanes. \\
\hline Curb & $\begin{array}{l}\text { For each side } 3 \text { categories: (1) mountable curb; (2) nonmountable; (3) no curb. Reference } \\
\text { category was mountable curb. }\end{array}$ \\
\hline Traffic control devices & $\begin{array}{l}\text { Presence of traffic control devices (roundabout, speed bump, chicanes/chokers, lane } \\
\text { narrowing, and signals) versus no traffic controls. }\end{array}$ \\
\hline Crossing & Presence of crossings (zebra, signals, bridge) versus no crossings. \\
\hline Crossing aids & Presence of crossing aids (median, kerb extension) versus no crossing aids. \\
\hline Other routes & $\begin{array}{l}\text { Presence of alternate routes (lanes, path through park, no through road) versus no alternate } \\
\text { route. }\end{array}$ \\
\hline Intersections & Path-path and path-road intersection versus no intersection. \\
\hline Streetlights & For each side, presence of street lighting versus no street lights. \\
\hline Lighting on path & For each side, whether lighting covered the path or not. \\
\hline Destinations & $\begin{array}{l}\text { The location provided access to services or other destinations (e.g., park, convenience store, } \\
\text { businesses) versus no destinations. }\end{array}$ \\
\hline Surveillance & Location could be observed from $\geq 75 \%$ versus less than $75 \%$. \\
\hline Maintenance & Location gardens and verges were $>75 \%$ well maintained versus less than $75 \%$. \\
\hline Verge trees & Presence of tress along the verge versus no trees. \\
\hline Tree height & Tall or medium sized trees versus small trees. \\
\hline Cleanliness & Location is clean (free of debris, garbage, graffiti, etc.) versus some uncleanliness. \\
\hline Natural features & Presence of parks, green space, river, lakes, and so forth. \\
\hline Path width & Path is 150 centimetres or less versus wider than 150 centimetres. \\
\hline Age & $\leq 14$ years old versus $\geq 15$ years old. \\
\hline Bicyclist speed (“speed”) & $<15 \mathrm{~km} / \mathrm{hr}$ versus $\geq 15 \mathrm{~km} / \mathrm{hr}$ \\
\hline Bicycling faster than usual ("riding fast") & Bicyclist reported "cycling faster than usual" at the time of the incident. \\
\hline Peak time & $\begin{array}{l}\text { Peak time (Monday-Friday 06:31-08:30 and 16:01-18:00) versus off-peak time and } \\
\text { weekends (Saturday and Sunday) }\end{array}$ \\
\hline
\end{tabular}

were divided into six groups including traffic factors (e.g., traffic volume), land use (e.g., types of buildings), path characteristics (e.g., path material), roadway characteristics (e.g., number of lanes), safety features (e.g., surveillance), and aesthetics (e.g., cleanliness). Table 1 presents a summary of the definitions of environmental characteristics assessed in the audits.

2.3. Statistical Analysis. The characteristics of locations were described by case and control status. Using a complete case analysis, conditional logistic regression was used to examine the effect of each exposure (i.e., 37 environmental characteristics) on the outcomes of interest while controlling for confounders. The number of matched sets in the study limited the number of potential independent variables that could be examined in the conditional logistic regression. It has been suggested that for modeling, the number of independent variables should not exceed $10 \%$ of the number of participants in the least frequent outcome category (in this analysis, cases) [23]. Given our matched design, this 


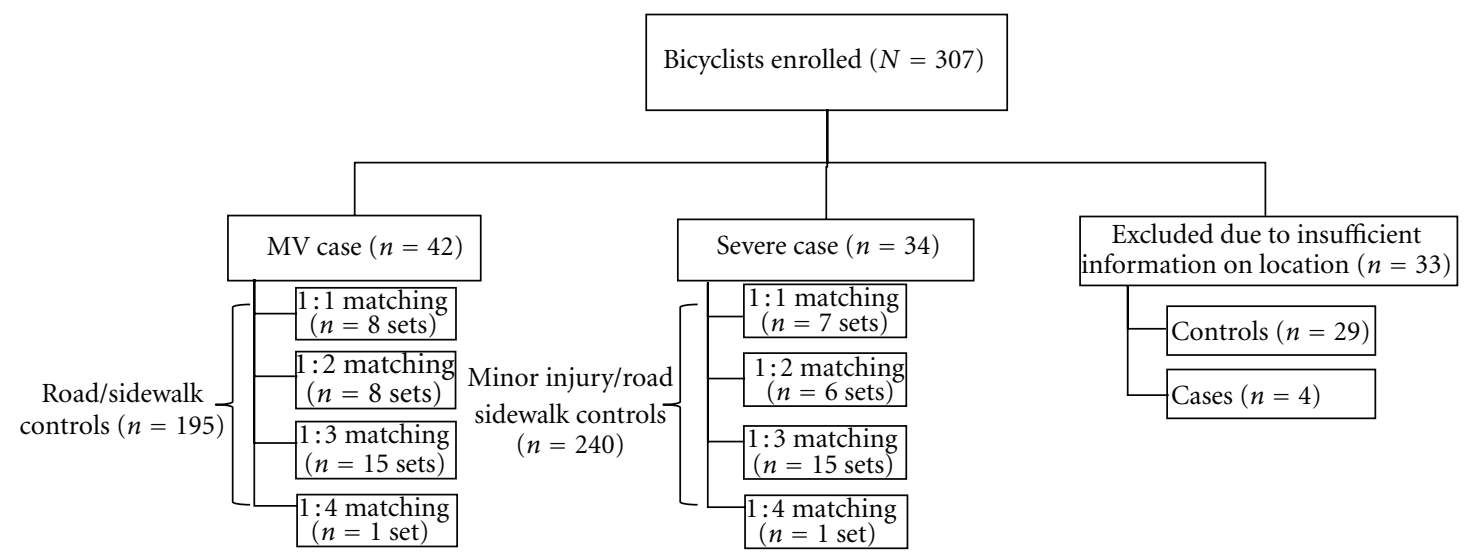

FIGURE 1: Study sample selection process for matched cases and controls.

guideline was applied to the number of discordant sets [24]. It has also been suggested that the "rule" can be relaxed, allowing the researcher to explore more independent variables to assess confounding [25]. We adopted this approach given the importance of considering known individual risk factors for bicycle injuries. Potential confounders were added to the model individually, and if any of the confounders changed the crude estimate by $>15 \%$ [25], it was retained. If more than one variable changed the estimate by $15 \%$, the one which produced the greatest change was retained. Potential confounders included age, sex, bicycling faster than usual, and self-reported bicyclist speed $[10,26,27]$. Although alcohol use has been shown to be associated with severe bicycling injuries, it was not included as a potential confounder because of its low prevalence in the study sample. "Not applicable" or "unknown" data were treated as missing values and thus were not included in the logistic regression estimates. Adjusted odds ratios (ORs) and corresponding $95 \%$ confidence intervals (CIs) were calculated.

To adjust for multiple confounders simultaneously, we conducted a sensitivity analysis where the matching was unlinked. Unconditional logistic regression was used, and the original matching criteria were added as a variable in the model, in addition to potential confounders. The results of the unmatched analysis were compared with the matched results. Again, we relaxed the 10\% "rule" [23], and potential confounders were added to the model following a 5-9 event per variable guideline $[24,25,28]$.

Ethical approval was granted from the University of Calgary Conjoint Health Research Ethics Board and the University of Alberta Health Research Ethics Board. All patients gave informed consent.

\section{Results}

In total, 274 injury sites were audited (Figure 1). There were 151 audits conducted in Edmonton, and 123 in Calgary. Six MV cases were also included in the severe case group. Twenty-nine controls and 4 cases were excluded from the study because they did not provide enough details about the crash location for auditors to visit the sites. We chose to report differences of at least $20 \%$ in the proportions of either case group and associated controls with a particular feature (Table 2) and estimates that suggested at least a 50\% change in the odds of MV collision or severe injury (Tables 3 and 4). None of the estimates suggesting a change less than $50 \%$ were statistically significant.

3.1. Characteristics of Case and Control Locations. Table 2 indicates that, compared with controls, a greater proportion of MV case sites had estimated vehicle speeds above $30 \mathrm{~km} / \mathrm{hr}$. While the predominant land use was housing, MV case locations occurred more often close to retail establishments. A higher proportion of MV case locations had path obstructions, $\geq 4$ lanes of traffic, or were intersections. Natural features were more prevalent at MV control compared with case sites. A higher proportion of severe injury control sites had sidewalks, roads in good condition, lighting over the path, or high surveillance. A higher proportion of severe case sites had $\geq 4$ lanes of traffic.

3.2. Risk Factors for $M V$ Collisions. From Table 3, in the matched analysis, compared with low traffic volume locations, medium and high volume sites were associated with higher odds of MV collisions. When the volume estimates were adjusted for sex (not shown), the estimated OR for high volume was 2.92 (95\% CI $[1.07,7.96])$, compared with low volume. The presence of retail or service establishments, path obstructions, parking restrictions, nonmountable curbs, traffic control devices, intersections, or destinations, each significantly increased the odds of being involved in a collision with an MV. The odds of a collision with an MV were lower in locations where natural features were present compared with locations where natural features were absent.

The results of the unmatched analysis were similar to the conditional logistic regression estimates (Table 3 ). The estimates for traffic volume, retail, path obstructions, destinations, and natural features were comparable, with some increase in precision demonstrated by narrower confidence intervals. After adjusting for multiple confounders the 
TABLE 2: Bicycle crash location characteristics by case and control groups.

\begin{tabular}{|c|c|c|c|c|c|c|c|c|}
\hline & $\begin{array}{c}\text { MV controls } \\
n=195\end{array}$ & $(\%)$ & $\begin{array}{c}\text { MV cases } \\
n=42\end{array}$ & $(\%)$ & $\begin{array}{c}\text { Severe controls } \\
n=240\end{array}$ & $(\%)$ & $\begin{array}{c}\text { Severe cases } \\
\quad n=34\end{array}$ & $(\%)$ \\
\hline \multicolumn{9}{|l|}{ Traffic and land use characteristics } \\
\hline Estimated avg. speed $>30 \mathrm{~km} / \mathrm{hr}$ & 121 & $(62.1)$ & 35 & (83.3) & 134 & $(55.8)$ & 22 & $(64.7)$ \\
\hline $\mathrm{n} / \mathrm{a}$ & 8 & $(4.1)$ & 0 & $(0.0)$ & 38 & $(15.8)$ & 7 & $(20.6)$ \\
\hline Unknown & 25 & $(12.8)$ & 1 & $(2.4)$ & 25 & $(10.4)$ & 1 & $(2.9)$ \\
\hline \multicolumn{9}{|l|}{ Predominant feature } \\
\hline Housing & 114 & $(58.5)$ & 17 & $(40.5)$ & 122 & $(50.8)$ & 15 & $(44.1)$ \\
\hline Retail & 7 & $(3.6)$ & 10 & $(23.8)$ & 12 & $(5.0)$ & 5 & $(14.7)$ \\
\hline Nature & 34 & $(17.4)$ & 4 & $(9.5)$ & 58 & $(24.2)$ & 6 & $(17.6)$ \\
\hline \multicolumn{9}{|l|}{ Path characteristics (side 1) } \\
\hline \multicolumn{9}{|l|}{ Path type } \\
\hline No path & 19 & $(9.7)$ & 5 & $(11.9)$ & 21 & $(8.8)$ & 3 & $(8.8)$ \\
\hline Sidewalk & 137 & $(70.3)$ & 30 & $(71.4)$ & 154 & $(64.2)$ & 20 & $(58.8)$ \\
\hline Shared with markings & 11 & $(5.6)$ & 1 & $(2.4)$ & 26 & $(10.8)$ & 6 & $(17.6)$ \\
\hline Shared no markings & 28 & $(14.4)$ & 6 & $(14.3)$ & 39 & $(16.3)$ & 5 & $(14.7)$ \\
\hline \multicolumn{9}{|l|}{ Path location } \\
\hline Within $1 \mathrm{~m}$ of road & 114 & $(58.5)$ & 30 & $(71.4)$ & 128 & $(53.3)$ & 16 & $(47.1)$ \\
\hline Btw 1 and $3 \mathrm{~m}$ of road & 33 & $(16.9)$ & 6 & (14.3) & 33 & (13.8) & 7 & (20.6) \\
\hline$>3 \mathrm{~m}$ from road & 28 & $(14.4)$ & 1 & $(2.4)$ & 54 & (22.5) & 8 & (23.5) \\
\hline $\mathrm{n} / \mathrm{a}$ & 19 & $(9.7)$ & 5 & $(11.9)$ & 21 & $(8.8)$ & 3 & $(8.8)$ \\
\hline Unknown & 1 & $(0.5)$ & 0 & $(0.0)$ & 4 & $(1.7)$ & 0 & $(0.0)$ \\
\hline Good condition & 111 & $(56.9)$ & 20 & $(47.6)$ & 135 & $(56.3)$ & 15 & $(44.1)$ \\
\hline $\mathrm{n} / \mathrm{a}$ & 19 & $(9.7)$ & 5 & (11.9) & 21 & $(8.8)$ & 3 & $(8.8)$ \\
\hline Any obstructions & 79 & $(40.5)$ & 22 & $(52.4)$ & 103 & $(42.9)$ & 13 & $(38.2)$ \\
\hline $\mathrm{n} / \mathrm{a}$ & 19 & $(9.7)$ & 5 & (11.9) & 21 & $(8.8)$ & 3 & $(8.8)$ \\
\hline \multicolumn{9}{|l|}{ Path characteristics (side 2) } \\
\hline \multicolumn{9}{|l|}{ Path type } \\
\hline No path & 62 & $(31.8)$ & 8 & $(19.0)$ & 68 & $(28.3)$ & 7 & $(20.6)$ \\
\hline Sidewalk & 110 & $(56.4)$ & 26 & $(61.9)$ & 128 & $(53.3)$ & 14 & $(41.2)$ \\
\hline Shared with markings & 4 & $(2.1)$ & 1 & $(2.4)$ & 13 & $(5.4)$ & 4 & $(11.8)$ \\
\hline Shared no markings & 16 & $(8.2)$ & 6 & (14.3) & 24 & $(10.0)$ & 4 & (11.8) \\
\hline $\mathrm{n} / \mathrm{a}$ & 3 & $(1.5)$ & 0 & $(0.0)$ & 6 & $(2.5)$ & 5 & $(14.7)$ \\
\hline Unknown & 0 & $(0.0)$ & 1 & $(2.4)$ & 1 & $(0.4)$ & 0 & $(0.0)$ \\
\hline \multicolumn{9}{|l|}{ Path location } \\
\hline Within $1 \mathrm{~m}$ of road & 80 & $(41.0)$ & 25 & $(59.5)$ & 93 & $(38.8)$ & 12 & $(35.3)$ \\
\hline Btw 1 and $3 \mathrm{~m}$ of road & 32 & $(16.4)$ & 8 & $(19.0)$ & 36 & $(15.0)$ & 4 & $(11.8)$ \\
\hline$>3 \mathrm{~m}$ from road & 17 & $(8.7)$ & 0 & $(0.0)$ & 32 & $(13.3)$ & 6 & $(17.6)$ \\
\hline $\mathrm{n} / \mathrm{a}$ & 65 & $(33.3)$ & 8 & $(19.0)$ & 74 & $(30.8)$ & 12 & $(35.3)$ \\
\hline Unknown & 1 & $(0.5)$ & 1 & $(2.4)$ & 5 & $(2.1)$ & 0 & $(0.0)$ \\
\hline Good condition & 85 & $(43.6)$ & 21 & $(50.0)$ & 103 & $(42.9)$ & 13 & $(38.2)$ \\
\hline $\mathrm{n} / \mathrm{a}$ & 65 & $(33.3)$ & 8 & (19.0) & 74 & $(30.8)$ & 12 & (35.3) \\
\hline Any obstructions & 48 & $(24.6)$ & 19 & $(45.2)$ & 64 & (26.7) & 9 & $(26.5)$ \\
\hline $\mathrm{n} / \mathrm{a}$ & 65 & $(33.3)$ & 8 & $(19.0)$ & 74 & $(30.8)$ & 12 & $(35.3)$ \\
\hline \multicolumn{9}{|l|}{ Roadway characteristics } \\
\hline Marked bike lane & 8 & $(4.1)$ & 4 & $(9.5)$ & 11 & $(4.6)$ & 1 & $(2.9)$ \\
\hline $\mathrm{n} / \mathrm{a}$ & 0 & $(0.0)$ & 0 & $(0.0)$ & 30 & $(12.5)$ & 7 & (20.6) \\
\hline Unknown & 3 & $(1.5)$ & 1 & $(2.4)$ & 3 & $(1.3)$ & 1 & $(2.9)$ \\
\hline Good road condition & 132 & $(67.7)$ & 25 & $(59.5)$ & 144 & $(60.0)$ & 13 & $(38.2)$ \\
\hline $\mathrm{n} / \mathrm{a}$ & 0 & $(0.0)$ & 0 & $(0.0)$ & 30 & $(12.5)$ & 7 & $(20.6)$ \\
\hline
\end{tabular}


TABle 2: Continued.

\begin{tabular}{|c|c|c|c|c|c|c|c|c|}
\hline & $\begin{array}{c}\text { MV controls } \\
n=195\end{array}$ & $(\%)$ & $\begin{array}{c}\text { MV cases } \\
n=42\end{array}$ & $(\%)$ & $\begin{array}{c}\text { Severe controls } \\
n=240\end{array}$ & $(\%)$ & $\begin{array}{c}\text { Severe cases } \\
n=34\end{array}$ & $(\%)$ \\
\hline$>4$ lanes of traffic & 62 & $(31.8)$ & 23 & $(54.8)$ & 70 & $(29.2)$ & 15 & $(44.1)$ \\
\hline $\mathrm{n} / \mathrm{a}$ & 0 & $(0.0)$ & 0 & $(0.0)$ & 30 & $(12.5)$ & 7 & $(20.6)$ \\
\hline Unknown & 4 & $(2.1)$ & 0 & $(0.0)$ & 4 & $(1.7)$ & 0 & $(0.0)$ \\
\hline Mountable curb (side 1) & 115 & $(59.0)$ & 22 & $(52.4)$ & 123 & $(51.3)$ & 14 & $(41.2)$ \\
\hline $\mathrm{n} / \mathrm{a}$ & 19 & $(9.7)$ & 2 & $(4.8)$ & 50 & $(20.8)$ & 8 & $(23.5)$ \\
\hline Unknown & 2 & $(1.0)$ & 0 & $(0.0)$ & 2 & $(0.8)$ & 0 & $(0.0)$ \\
\hline Traffic control devices & 130 & $(66.7)$ & 18 & $(42.9)$ & 133 & $(55.4)$ & 15 & $(44.1)$ \\
\hline $\mathrm{n} / \mathrm{a}$ & 0 & $(0.0)$ & 0 & $(0.0)$ & 30 & $(12.5)$ & 7 & $(20.6)$ \\
\hline Missing & 4 & $(2.1)$ & 0 & $(0.0)$ & 2 & $(0.8)$ & 2 & $(5.9)$ \\
\hline Intersections & 118 & $(60.5)$ & 36 & $(85.7)$ & 152 & $(63.3)$ & 22 & $(64.7)$ \\
\hline Unknown & 6 & $(3.1)$ & 0 & $(0.0)$ & 88 & $(36.7)$ & 12 & $(35.3)$ \\
\hline \multicolumn{9}{|l|}{ Safety characteristics } \\
\hline Lights over path (side 1) & 114 & $(58.5)$ & 27 & $(64.3)$ & 129 & $(53.8)$ & 15 & $(44.1)$ \\
\hline $\mathrm{n} / \mathrm{a}$ & 47 & $(24.1)$ & 10 & $(23.8)$ & 75 & $(31.3)$ & 12 & $(35.3)$ \\
\hline Unknown & 1 & $(0.5)$ & 0 & $(0.0)$ & 3 & $(1.3)$ & 0 & $(0.0)$ \\
\hline Lights over path (side 2) & 106 & $(54.4)$ & 30 & $(71.4)$ & 126 & $(52.5)$ & 13 & $(38.2)$ \\
\hline $\mathrm{n} / \mathrm{a}$ & 46 & $(23.6)$ & 5 & $(11.9)$ & 68 & $(28.3)$ & 12 & $(35.3)$ \\
\hline Unknown & 1 & $(0.5)$ & 0 & $(0.0)$ & 4 & (1.7) & 0 & $(0.0)$ \\
\hline Destinations & 92 & $(47.2)$ & 30 & $(71.4)$ & 116 & $(48.3)$ & 17 & $(50.0)$ \\
\hline Unknown & 0 & $(0.0)$ & 0 & $(0.0)$ & 1 & $(0.4)$ & 0 & $(0.0)$ \\
\hline High surveillance & 101 & $(51.8)$ & 19 & $(45.2)$ & 116 & $(48.3)$ & 10 & $(29.4)$ \\
\hline $\mathrm{n} / \mathrm{a}$ & 5 & $(2.6)$ & 0 & $(0.0)$ & 19 & $(7.9)$ & 5 & $(14.7)$ \\
\hline \multicolumn{9}{|l|}{ Aesthetic characteristics } \\
\hline Natural features & 105 & $(53.8)$ & 14 & $(33.3)$ & 133 & $(55.4)$ & 22 & $(64.7)$ \\
\hline Attractive for cycling & 169 & $(86.7)$ & 32 & $(76.2)$ & 208 & $(86.7)$ & 27 & $(79.4)$ \\
\hline Difficult for cycling & 48 & $(24.6)$ & 14 & $(33.3)$ & 66 & $(27.5)$ & 12 & $(35.3)$ \\
\hline Continuity & 172 & $(88.2)$ & 39 & $(92.9)$ & 210 & $(87.5)$ & 33 & $(97.1)$ \\
\hline $\mathrm{n} / \mathrm{a}$ & 1 & $(0.5)$ & 0 & $(0.0)$ & 1 & $(0.4)$ & 0 & $(0.0)$ \\
\hline Unknown & 7 & $(3.6)$ & 0 & $(0.0)$ & 7 & $(2.9)$ & 0 & $(0.0)$ \\
\hline
\end{tabular}

estimates for services, parking restrictions, curb design, and traffic control devices were no longer statistically significant.

3.3. Risk Factors for Severe Injury (Hospitalization). The matched analysis results in Table 4 suggest that traffic volume may be related to severe injuries; however, the result was not statistically significant. The presence of a retail establishment increased the odds of severe injury. Locations with a multiuse path had lower odds of severe injury compared with locations with a sidewalk. Good road conditions, compared with poor road condition, lowered the odds of severe injury. Nonmountable curbs increased the odds of severe injury.

The unmatched analysis results were similar to the matched results. The presence of retail land use remained an important predictor of severe injuries, while good road condition still reduced the odds of severe injury. The presence of street lighting and high surveillance from surrounding buildings both had a point estimate that indicated a reduction in the odds of a severe injury.
3.4. Audit Data Interrater Reliability. Ninety-seven locations were audited by two observers. Interrater agreement was generally high $(\geq 95 \%)$; most items had a $1 \%-2 \%$ difference in responses. Items with $\geq 5 \%$ differences between raters included path condition, slope, and obstructions. For land use, path, and roadway characteristics, Kappa $(\kappa)$ ranged from 0.3 for presence of offices and cleanliness to 0.9 for schools and number of lanes; overall, 78\% of items had at least substantial agreement $(\kappa \geq 0.61)$. For MV cases the proportion of items with substantial agreement was $60 \%$, compared with $73 \%$ for controls. For severe cases and minor injury controls, $76 \%$ of items had substantial agreement.

\section{Discussion}

This study provides a comprehensive description of the locations where bicycling injuries occurred, bringing attention to built environmental features that increase the likelihood of a bicyclist-MV collision or severe injury. Our results show 
TABLE 3: Matched and un-matched logistic regression estimates of the association between environment risk factors and MV/bicyclist collisions.

\begin{tabular}{|c|c|c|c|c|c|c|}
\hline & Matched OR & $95 \% \mathrm{CI}$ & Adjustment factors & Un-matched OR & $95 \% \mathrm{CI}$ & $\begin{array}{l}\text { Adjustment } \\
\text { factors }\end{array}$ \\
\hline \multicolumn{7}{|l|}{ Traffic volume } \\
\hline Low $^{\mathrm{a}}$ & 1 & Reference & $\mathrm{b}$ & 1 & Reference & $\mathrm{b}$ \\
\hline $\mathrm{Med}^{\mathrm{a}}$ & $5.13 *$ & $1.44,18.27$ & Riding fast & $3.49 *$ & $1.37,8.88$ & Age \\
\hline High $^{\mathrm{a}}$ & 2.34 & $0.75,7.24$ & Riding fast & $2.83^{*}$ & $1.24,6.42$ & Age \\
\hline High speed limit (>30 km/hr) & 3.18 & $0.62,16.41$ & $\mathrm{~b}$ & 2.59 & $0.87,7.71$ & b \\
\hline \multicolumn{7}{|l|}{ Land use } \\
\hline Offices & 8.8 & $0.99,78.16$ & $\mathrm{~b}$ & 3.01 & $0.73,12.36$ & $\begin{array}{l}\text { Age, day/time } \\
\text { and riding fast }\end{array}$ \\
\hline Retail & $5.56^{*}$ & $1.72,17.98$ & Age & $7.54^{*}$ & $3.15,18.03$ & Age and speed \\
\hline Industry & 2.07 & $0.28,15.43$ & $\mathrm{~b}$ & 3.70 & $0.48,28.82$ & Age and speed \\
\hline Services & $3.80^{*}$ & $1.29,11.69$ & $\mathrm{~b}$ & 2.02 & $0.96,4.23$ & Age \\
\hline Nature & 0.38 & $0.14,1.00$ & Speed & $0.44^{*}$ & $0.21,0.91$ & $\mathrm{~b}$ \\
\hline \multicolumn{7}{|l|}{ Path characteristics (side 1) } \\
\hline \multicolumn{7}{|l|}{ Type of path } \\
\hline Sidewalk & 1 & Reference & & 1 & Reference & \\
\hline No path & 1.66 & $0.14,19.75$ & Age & 1.30 & $0.43,3.89$ & Speed \\
\hline Multi-use path ${ }^{\#}$ & 0.63 & $0.16,2.51$ & Age & 1.05 & $0.41,2.68$ & Speed \\
\hline \multicolumn{7}{|c|}{ Path location (distance from road) } \\
\hline Within $1 \mathrm{~m}$ & 1 & Reference & & 1 & Reference & \\
\hline Btw 1 and $3 \mathrm{~m}$ & 1.02 & $0.26,3.95$ & Sex & 0.40 & $0.14,1.12$ & $\begin{array}{l}\text { Age and } \\
\text { day/time }\end{array}$ \\
\hline$>3 \mathrm{~m}$ & 0.17 & $0.02,1.53$ & Age & 0.16 & $0.02,1.29$ & $\begin{array}{l}\text { Age and } \\
\text { day/time }\end{array}$ \\
\hline Sloped path & 1.60 & $0.35,7.36$ & $\mathrm{~b}$ & 1.14 & $0.35,3.71$ & Riding fast \\
\hline Path obstructions & 1.05 & $0.38,2.93$ & Age & 1.80 & $0.88,3.70$ & b \\
\hline \multicolumn{7}{|l|}{ Path characteristics (side 2) } \\
\hline \multicolumn{7}{|l|}{ Type of path } \\
\hline Sidewalk & 1 & Reference & & 1 & Reference & \\
\hline No path & 0.38 & $0.12,1.26$ & Riding fast & 0.68 & $0.28,1.68$ & Age and speed \\
\hline Multi-use path ${ }^{\#}$ & 0.61 & $0.10,3.78$ & Riding fast & 1.69 & $0.59,4.85$ & Age and speed \\
\hline Sloped path & 0.15 & $0,1.99$ & $\mathrm{~b}$ & 0.72 & $0.18,2.98$ & $\begin{array}{l}\text { Day/time, riding } \\
\text { fast and speed }\end{array}$ \\
\hline Path obstructions & $3.83^{*}$ & $1.03,14.25$ & $\mathrm{~b}$ & $2.59^{*}$ & $1.13,5.90$ & Speed \\
\hline \multicolumn{7}{|l|}{ Roadway characteristics } \\
\hline Designated bike lane & 0.64 & $0.10,4.19$ & b & 1.83 & $0.42,8.02$ & $\begin{array}{l}\text { Day/time, riding } \\
\text { fast and age }\end{array}$ \\
\hline Parking restrictions & $3.88^{*}$ & $1.31,11.55$ & b & 1.74 & $0.85,3.55$ & Age \\
\hline \multicolumn{7}{|l|}{ Curb } \\
\hline Mountable & 1 & Reference & & 1 & Reference & \\
\hline Not mountable & $3.03 *$ & $1.04,8.82$ & Sex & 1.35 & $0.65,2.82$ & Riding fast \\
\hline No curb & 0.84 & $0.13,5.59$ & Sex & 0.55 & $0.12,2.56$ & Riding fast \\
\hline Curb cuts & 2.71 & $0.84,8.72$ & $\mathrm{~b}$ & 0.82 & $0.38,1.78$ & $\begin{array}{l}\text { Riding fast and } \\
\text { age }\end{array}$ \\
\hline Traffic control devices & $2.74^{*}$ & $1.02,7.35$ & Riding fast & 1.59 & $0.74,3.45$ & $\begin{array}{l}\text { Age and } \\
\text { day/time }\end{array}$ \\
\hline Intersection & $6.89^{*}$ & $1.48,32.14$ & $\mathrm{~b}$ & $2.83^{*}$ & $1.11,7.20$ & Age \\
\hline Crossings & 1.68 & $0.62,4.54$ & $\mathrm{~b}$ & 1.54 & $0.73,3.26$ & $\begin{array}{l}\text { Age and } \\
\text { day/time }\end{array}$ \\
\hline Crossing aids & 0.4 & $0.10,1.52$ & b & 0.43 & $0.16,1.18$ & Age and speed \\
\hline \multicolumn{7}{|l|}{ Safety characteristics } \\
\hline Street lights (side 2) & 2.38 & $0.51,10.99$ & $\mathrm{~b}$ & 1.54 & $0.43,5.58$ & Age \\
\hline Lighting over path (side 2) & 1.03 & $0.30,3.53$ & $\mathrm{~b}$ & 1.70 & $0.69,4.16$ & $\mathrm{~b}$ \\
\hline Destinations & 2.4 & $1.01,6.00^{*}$ & Sex & $2.35^{*}$ & $1.11,4.97$ & Riding fast \\
\hline
\end{tabular}


TABle 3: Continued.

\begin{tabular}{|c|c|c|c|c|c|c|}
\hline & Matched OR & $95 \% \mathrm{CI}$ & Adjustment factors & Un-matched OR & $95 \% \mathrm{CI}$ & $\begin{array}{l}\text { Adjustment } \\
\text { factors }\end{array}$ \\
\hline \multicolumn{7}{|l|}{ Aesthetic characteristics } \\
\hline$>1$ tree/block (side 1$)$ & 3.25 & $0.37,28.46$ & $\mathrm{~b}$ & 1.71 & $0.63,4.63$ & Riding fast \\
\hline Tall trees (side 1 ) & 2.27 & $0.26,20.06$ & b & 1.08 & $0.21,5.45$ & Riding fast \\
\hline Natural views & $0.2^{*}$ & $0.07,0.69$ & Age & $0.43^{*}$ & $0.21,0.86$ & $\mathrm{~b}$ \\
\hline Difficult for bicycling & 2.00 & $0.68,5.92$ & $\mathrm{~b}$ & 1.92 & $0.55,6.66$ & $\begin{array}{l}\text { Speed and } \\
\text { day/time }\end{array}$ \\
\hline
\end{tabular}

MV: motor vehicle; OR: odds ratio; CI: confidence interval.

* Represents significance based on CI not including the null value.

${ }^{a}$ Low volume: $\leq 250$ vehicles/hr, medium volume: $250-749$ vehicles/hr, high volume: $\geq 750$ vehicles/hr.

${ }^{b}$ If model could not accommodate the addition of one or more covariates or there was no evidence of confounding, the crude estimate was retained.

that traffic volume is a significant risk factor for bicycleMV collisions. Medium and high volume presented at least a twofold increase in the odds of collision compared with low volume roads. At intersections the odds of collision were much higher than at nonintersection locations. Good road conditions were associated with a reduction in the odds of severe injury. When we examined the odds ratio estimates associated with various types of land use, bicyclists were more at risk near retail establishments. Some aesthetic and safety items, such as streetlights and high surveillance showed a $30 \%-40 \%$ reduction in the odds of severe injury. We examined the effect of several potential confounders previously shown to be related to bicycling injuries: age, sex, self-reported bicyclist speed, bicycling faster than usual, and time of day $[10,12,29]$. In both the matched and unmatched analyses, adjustment for age had the greatest impact on the magnitude of the odds ratio estimates between the environmental characteristics and injury. This is consistent with other research where age has been identified as one of the major risk factors for injury in bicyclists $[10,11]$.

The estimates for high traffic volume were lower than those for medium volume, which may be related to road configuration. High volume roads might be thoroughfares where traffic flow is uninterrupted (e.g., highways), creating fewer opportunities for bicyclists and vehicles to cross paths. Alternatively, medium volume locations might be areas with many intersections, presenting more opportunities for encounters. While few studies have directly examined the link between traffic volume and bicyclist injury, it has been shown that roads designed to accommodate more traffic, such as arterial and divided roads, increase the overall risk of bicycle-vehicle collisions [30, 31].

Significantly lower odds of severe injury were observed for locations with multiuse paths compared with sidewalks in the matched analysis. Bicycle paths are reported to be favoured by many and have been linked to increased bicycling [32]. Other studies have found an increased risk of injury on sidewalks compared with off-road paths $[17,18,33]$, a reduced risk of injury on paths compared with the road [34] and reduced odds of fatality or hospitalization when bicycling on a facility other than the road such as sidewalks, driveways, or multiuse paths $[11,29]$. This growing evidence suggests that separating bicyclists from pedestrians and MVs with facilities like dedicated bicycling lanes can reduce the risk of injury.

For land use, the presence of retail establishments increased the odds of MV collisions and severe injuries. It is likely that these commercial sites have more traffic volume, population density, intersections, and distractions, creating opportunities for bicyclist-MV encounters. The relationship between commercial establishments and bicyclistMV crashes has been found elsewhere with the presence of strip malls and big box stores (e.g., Wal-Mart), which were associated with an increased number of bicyclist-MV encounters compared with noncommercial locations [31]. This suggests that safety gains could be made by diverting bicyclists away from heavy traffic in commercial areas (e.g., parking lots), perhaps by locating parking lots at the rear of shops or by providing designated bicycle path access to shops.

Streetlights and surveillance were associated with significant reductions in the odds of severe injury. It may be that driving behaviour is influenced by having "eyes on the street" (e.g., people drive slower when they are aware of people watching them), resulting in fewer or less severe bicycling injuries. Alternatively, traffic volume may be higher in areas with less surveillance (e.g., arterial roads). While few studies have examined safety or aesthetic features and injuries together, some studies have examined the effect of street lighting. These studies have shown that severe injuries are more likely in unlit areas, and that lighting reduces injuries in rural areas $[26,35,36]$. It is important to keep this evidence in mind, especially in locations like Alberta where it is dark early in the morning and late in the afternoon for much of the year, which correspond to commuting times. This is an important finding from a planning perspective and suggests that more street lighting or better light coverage for roadways and pathways could help prevent injuries.

When comparing the factors related to MV and severe injury outcomes we found that factors related to one outcome were not necessarily related to the other. Recognizing that features of the environment associated with MV collisions and severe injuries may differ from one another is important for planners, as it signals that multiple design elements need to be considered in order to reduce the occurrence of each type of event. Focusing on the factors that are identified as predictors of both outcomes is crucial. 
TABLE 4: Matched and un-matched logistic regression estimates of the association between environment risk factors and severe bicyclist injury.

\begin{tabular}{|c|c|c|c|c|c|c|}
\hline & Matched OR & $95 \% \mathrm{CI}$ & Adjustment factors & Un-matched OR & $95 \% \mathrm{CI}$ & Adjustment factors \\
\hline \multicolumn{7}{|l|}{ Traffic volume } \\
\hline Low $^{a}$ & 1 & Reference & & 1 & Reference & \\
\hline $\mathrm{Med}^{\mathrm{a}}$ & 3.20 & $0.63,16.25$ & Riding fast & 1.22 & $0.37,4.01$ & Age \\
\hline High $^{\mathrm{a}}$ & 2.01 & $0.51,7.94$ & Riding fast & 1.53 & $0.61,3.85$ & Age \\
\hline Avg. traffic speed $(>30 \mathrm{~km} / \mathrm{hr})$ & 1.7 & $0,3.91$ & $\mathrm{~b}$ & 4.13 & $0.89,19.11$ & Speed and riding fast \\
\hline High speed limit $(>30 \mathrm{~km} / \mathrm{hr})$ & 1.85 & $0.46,7.47$ & $\mathrm{~b}$ & 1.14 & $0.41,3.21$ & $\mathrm{~b}$ \\
\hline \multicolumn{7}{|l|}{ Land use } \\
\hline Retail & $8.12^{*}$ & $1.66,39.7$ & $\mathrm{~b}$ & $2.53^{*}$ & $1.10,5.83$ & Age \\
\hline School & 0.24 & $0.03,1.05$ & $\mathrm{~b}$ & 0.35 & $0.04,2.84$ & Age and speed \\
\hline Nature & 0.41 & $0.14,1.24$ & Age & 1.25 & $0.60,2.57$ & $\mathrm{~b}$ \\
\hline \multicolumn{7}{|l|}{ Path characteristics (side 1) } \\
\hline \multicolumn{7}{|l|}{ Type of path } \\
\hline Sidewalk & 1 & Reference & & 1 & Reference & \\
\hline No path & 1.29 & $0.24,6.81$ & Riding fast & 1.10 & $0.30,4.02$ & $\mathrm{~b}$ \\
\hline Multi-use path ${ }^{\#}$ & $0.24^{*}$ & $0.08,0.77$ & Riding fast & 1.30 & $0.59,2.87$ & $\mathrm{~b}$ \\
\hline \multicolumn{7}{|c|}{ Path location (distance from road) } \\
\hline Within $1 \mathrm{~m}$ of road & 1 & Reference & & 1 & Reference & \\
\hline Btw 1 and $3 \mathrm{~m}$ of road & 0.54 & $0.14,2.09$ & Age & 1.68 & $0.59,4.81$ & Speed \\
\hline$>3 \mathrm{~m}$ from road & 0.48 & $0.16,1.45$ & Age & 1.42 & $0.52,3.85$ & Speed \\
\hline Sloped path & 0.42 & $0,1.63$ & $\mathrm{~b}$ & 1.83 & $0.71,4.76$ & Speed \\
\hline Path obstructions & 0.36 & $0.13,1.01$ & Age & 0.81 & $0.38,1.74$ & $\mathrm{~b}$ \\
\hline \multicolumn{7}{|l|}{ Path characteristics (side 2) } \\
\hline \multicolumn{7}{|l|}{ Type of path } \\
\hline Sidewalk & 1 & Reference & & 1 & Reference & \\
\hline No path & 1.14 & $0.36,3.62$ & Age & 0.86 & $0.28,2.65$ & Age and speed \\
\hline Multi-use path ${ }^{\#}$ & 0.40 & $0.10,1.68$ & Age & 2.12 & $0.73,6.21$ & Age and speed \\
\hline \multicolumn{7}{|c|}{ Path location (distance from road) } \\
\hline Within $1 \mathrm{~m}$ & 1 & Reference & & 1 & Reference & \\
\hline Btw 1 and $3 \mathrm{~m}$ & 0.11 & $0.01,1.64$ & Age & 0.96 & $0.28,3.31$ & Speed \\
\hline$>3 \mathrm{~m}$ & 0.36 & $0.06,2.06$ & Age & 1.95 & $0.59,6.49$ & Speed \\
\hline Sloped path & 1.11 & $0.23,5.32$ & b & 1.93 & $0.65,5.75$ & $\mathrm{~b}$ \\
\hline Path obstructions & 3.32 & $0.65,16.9$ & $\mathrm{~b}$ & 1.10 & $0.45,2.73$ & $\mathrm{~b}$ \\
\hline \multicolumn{7}{|l|}{ Roadway characteristics } \\
\hline Good road condition & $0.25^{*}$ & $0.07,0.96$ & $\mathrm{~b}$ & $0.43^{*}$ & $0.19,0.96$ & $\mathrm{~b}$ \\
\hline$>4$ lanes of traffic & 2.59 & $0.80,8.4$ & b & 2.31 & $0.87,6.16$ & $\begin{array}{l}\text { Age, speed, and riding } \\
\text { fast }\end{array}$ \\
\hline \multicolumn{7}{|l|}{ Curb } \\
\hline Mountable & 1 & Reference & & 1 & Reference & \\
\hline Non-mountable & $4.51^{*}$ & $1.08,18.8$ & Sex & 1.62 & $0.71,3.71$ & $\mathrm{~b}$ \\
\hline No curb & 0.34 & $0.04,3.17$ & Sex & 0.44 & $0.05,3.53$ & $\mathrm{~b}$ \\
\hline Crossings & 1.1 & $0.39,3.15$ & $\mathrm{~b}$ & 1.85 & $0.75,4.58$ & Speed \\
\hline Other routes & 0.44 & $0.16,1.16$ & Riding fast & 0.75 & $0.34,1.68$ & Speed \\
\hline \multicolumn{7}{|l|}{ Safety characteristics } \\
\hline Street lights (side 1) & 1.90 & $0.70,5.12$ & Age & 0.78 & $0.34,1.79$ & Speed \\
\hline Street lights (side 2) & 0.89 & $0.29,2.77$ & $\mathrm{~b}$ & $0.38^{*}$ & $0.15,0.97$ & Age and speed \\
\hline Lighting over path (side 1) & 0.36 & $0.07,1.86$ & $\mathrm{~b}$ & 0.43 & $0.15,1.22$ & Sex \\
\hline Lighting over path (side 2) & 0.58 & $0.16,2.15$ & $\mathrm{~b}$ & 0.39 & $0.15,1.04$ & Sex \\
\hline High surveillance & 0.53 & $0.17,1.71$ & $\mathrm{~b}$ & $0.32^{*}$ & $0.13,0.82$ & Speed \\
\hline
\end{tabular}


TABle 4: Continued.

\begin{tabular}{ccccccc}
\hline & Matched OR & $95 \%$ CI & Adjustment factors & Un-matched OR & 95\% CI & Adjustment factors \\
\hline Aesthetic characteristics & & & & & & \\
$>1$ tree/block (side 1) & 2.19 & $0.41,11.78$ & b & 2.07 & $0.57,7.53$ & Speed \\
$>1$ tree/block (side 2) & 1.98 & $0.22,17.88$ & b & 1.75 & $0.48,6.42$ & Speed \\
Clean & 1.79 & $0.59,5.43$ & Age & 1.52 & $0.60,3.85$ & b \\
Attractive for bicycling & 0.4 & $0.13,1.23$ & b & 0.49 & $0.18,1.32$ & Age and speed \\
Continuity of path & 3.0 & $0.35,25.96$ & b & 2.34 & $0.29,19.04 \quad$ Age, speed, and riding \\
\end{tabular}

MV: motor vehicle; OR: odds ratio; CI: confidence interval.

* Represents significance based on CI not including the null value.

a Low volume: $\leq 250$ vehicles/hr, medium volume: $250-749$ vehicles/hr, high volume: $\geq 750$ vehicles/hr.

${ }^{b}$ If model could not accommodate the addition of one or more covariates, the crude estimate was retained.

4.1. Limitations. This study has some limitations that require discussion. We collected information on potential confounders; however, it is possible that factors we did not anticipate or collect information on could be independently related to the outcomes and the characteristics we examined. One such possible confounder is bicyclist volume. While we did count bicyclists, the majority of the sites we visited had low/no bicyclist volume. Given the lack of information on this factor, it was not included in the adjusted analysis. It has been suggested that greater bicyclist volume is associated with a reduction in the number of injuries (i.e., the "safety in numbers" effect); however, a causal relationship has not been established $[4,37,38]$. We did examine bicyclist volume as an independent predictor of MV events and severe injuries and did not find evidence of an association.

To determine the audit sites, we relied on the participant's description of the crash location. Some patients had trouble remembering the exact crash site or their direction of travel at the time. The information they provided is subject to limitation of recall, especially if the patient was interviewed sometime after the event. However, the average time between the injury and the audit date was 48 days, and nearly $80 \%$ of audits were conducted within 2 months of the injury date. Many interviews were conducted by telephone, and resources did not permit us to provide maps for patients to pinpoint their crash site.

Bicyclists who could not provide sufficient details about the crash location for it to be accurately identified were excluded from the analysis. If these bicyclists differed systematically from those included in the sample, it could introduce selection bias. To examine this potential bias, the excluded bicyclists were compared with the overall study sample. Few differences were detected between the two groups; compared with the study sample, a slightly higher proportion of excluded bicyclists were 13-17 years old, and they had a lower proportion of helmet use. Because of these minor differences, it may be that there were fewer adolescents in our sample than would have been included otherwise. Adjustment for age in the analysis would have eliminated this concern. In addition, because excluded bicyclists made up a very small proportion of the overall sample, their exclusion is unlikely to have had any major effect on the findings.
While there is potential for misclassification of the built environment characteristics of audited locations, when we examined the reliability of the audit data from locations where two observers completed observations, there was no indication that items were inconsistently recorded. Kappa values indicated "substantial" to "almost perfect" agreement for the majority of items, and differences in agreement between case and control locations were minor. In addition, we used the data from the blinded auditor for all analyses, reducing the likelihood of observer bias.

\section{Conclusion}

The built environment cannot be overlooked in injury prevention strategies. Creating safe, activity friendly environments is vital to encouraging higher levels of physical activity participation [8], especially considering the obesity epidemic and the shift towards encouraging eco-friendly transportation. Our findings point to specific built environmental characteristics including traffic volume, land use, path designs, and roadway features as risk factors for MV collisions or severe injuries. This information should provide urban and transportation planners with robust evidence upon which to base decisions regarding environments that are safe and conducive to bicycling. Furthermore, by disseminating this information to end users, bicyclists will be aware of the dangers posed by certain features, enabling them to make safe route choices.

\section{Abbreviations}

ED: Emergency department

MV: Motor vehicle

OR: Odds ratio

CI: Confidence interval.

\section{Acknowledgments}

The authors would like to thank the clinical and research staff at the Alberta Children's Hospital, Foothills Medical Centre, Rockyview Hospital, and Peter Lougheed Hospital in 
Calgary, and the Stollery Children's Hospital, University of Alberta Hospital, and North East Community Health Centre in Edmonton.

\section{References}

[1] L. B. Andersen, P. Schnohr, M. Schroll, and H. O. Hein, "Allcause mortality associated with physical activity during leisure time, work, sports, and cycling to work," Archives of Internal Medicine, vol. 160, no. 11, pp. 1621-1628, 2000.

[2] M. Fenton, "Battling America's epidemic of physical inactivity: building more walkable, livable communities," Journal of Nutrition Education and Behavior, vol. 37, supplement 2, pp. S115-S120, 2005.

[3] D. R. Bassett, J. Pucher, R. Buehler, D. L. Thompson, and S. E. Crouter, "Walking, cycling, and obesity rates in Europe, North America and Australia," Journal of Physical Activity and Health, vol. 5, no. 6, pp. 795-814, 2008.

[4] J. Pucher and R. Buehler, "Making cycling irresistible: lessons from the Netherlands, Denmark and Germany," Transport Reviews, vol. 28, no. 4, pp. 495-528, 2008.

[5] J. Pucher and R. Buehler, "Why Canadians cycle more than Americans: a comparative analysis of bicycling trends and policies," Transport Policy, vol. 13, no. 3, pp. 265-279, 2006.

[6] J. Pucher, J. Dill, and S. Handy, "Infrastructure, programs, and policies to increase bicycling: an international review," Preventive Medicine, vol. 50, supplement, pp. S106-S125, 2010.

[7] B. E. Saelens, J. F. Sallis, and L. D. Frank, "Environmental correlates of walking and cycling: findings from the transportation, urban design, and planning literatures," Annals of Behavioral Medicine, vol. 25, no. 2, pp. 80-91, 2003.

[8] K. M. Pollack, C. Kercher, S. Frattaroli, C. Asa-Peek, D. Sleet, and F. P. Rivara, "Towards environments and policies that promote injury-free active living-it wouldn't hurt," Health \& Place, vol. 18, no. 1, pp. 106-114, 2012.

[9] Statistics Canada, Commuting Patterns and Places of Work of Canadians, Statistics Canada, Ottawa, Canada, 2006.

[10] F. P. Rivara, D. C. Thompson, and R. S. Thompson, "Epidemiology of bicycle injuries and risk factors for serious injury," Injury Prevention, vol. 3, no. 2, pp. 110-114, 1997.

[11] T. J. Mehan, R. Gardner, G. A. Smith, and L. B. McKenzie, "Bicycle-related injuries among children and adolescents in the United States," Clinical Pediatrics, vol. 48, no. 2, pp. 166173, 2009.

[12] L. B. Meuleners, A. H. Lee, and C. Haworth, "Emergency presentations by vulnerable road users: implications for injury prevention," Injury Prevention, vol. 12, no. 1, pp. 12-14, 2006.

[13] G. Li, S. P. Baker, J. E. Smialek, and C. A. Soderstrom, "Use of alcohol as a risk factor for bicycling injury," The Journal of the American Medical Association, vol. 285, no. 7, pp. 893-896, 2001.

[14] D. C. Thompson, F. P. Rivara, and R. Thompson, "Helmets for preventing head and facial injuries in bicyclists," Cochrane Database of Systematic Reviews, no. 2, Article ID CD001855, 2000.

[15] G. R. McCormack and A. Shiell, "In search of causality: a systematic review of the relationship between the built environment and physical activity among adults," International Journal of Behavioural Nutrition and Physical Activity, vol. 8, article 125, 2012.

[16] W. Wendel-Vos, M. Droomers, S. Kremers, J. Brug, and F. van Lenthe, "Potential environmental determinants of physical activity in adults: a systematic review," Obesity Reviews, vol. 8, no. 5, pp. 425-440, 2007.

[17] L. Aultman-Hall and F. L. Hall, "Ottawa-Carleton commuter cyclist on- and off-road incident rates," Accident Analysis and Prevention, vol. 30, no. 1, pp. 29-43, 1998.

[18] L. Aultman-Hall and M. G. Kaltenecker, "Toronto bicycle commuter safety rates," Accident Analysis and Prevention, vol. 31, no. 6, pp. 675-686, 1999.

[19] S. Daniels, T. Brijs, E. Nuyts, and G. Wets, "Injury crashes with bicyclists at roundabouts: influence of some location characteristics and the design of cycle facilities," Journal of Safety Research, vol. 40, no. 2, pp. 141-148, 2009.

[20] S. Daniels, E. Nuyts, and G. Wets, "The effects of roundabouts on traffic safety for bicyclists: an observational study," Accident Analysis and Prevention, vol. 40, no. 2, pp. 518-526, 2008.

[21] S. Wells, B. Mullin, R. Norton et al., "Motorcycle rider conspicuity and crash related injury: case-control study," British Medical Journal, vol. 328, no. 7444, pp. 857-860, 2004.

[22] T. J. Pikora, F. C. L. Bull, K. Jamrozik, M. Knuiman, B. Giles-Corti, and R. J. Donovan, "Developing a reliable audit instrument to measure the physical environment for physical activity," American Journal of Preventive Medicine, vol. 23, no. 3, pp. 187-194, 2002.

[23] F. E. J. Harrell, K. L. Lee, and D. B. Mark, "Multivariable prognostic models: issues in developing models, evaluating assumptions and adequacy, and measuring and reducing errors," Statistics in Medicine, vol. 15, pp. 361-387, 1996.

[24] S. Greenland, J. A. Schwartzbaum, and W. D. Finkle, "Problems due to small samples and sparse data in conditional logistic regression analysis," American Journal of Epidemiology, vol. 151, no. 5, pp. 531-539, 2000.

[25] R. M. Mickey and S. Greenland, "The impact of confounder selection criteria on effect estimation," American Journal of Epidemiology, vol. 129, no. 1, pp. 125-137, 1989.

[26] M. Bíl, M. Bílová, and I. Müller, "Critical factors in fatal collisions of adult cyclists with automobiles," Accident Analysis and Prevention, vol. 42, no. 6, pp. 1632-1636, 2010.

[27] S. Chong, R. Poulos, J. Olivier, W. L. Watson, and R. Grzebieta, "Relative injury severity among vulnerable non-motorised road users: comparative analysis of injury arising from bicyclemotor vehicle and bicycle-pedestrian collisions," Accident Analysis and Prevention, vol. 42, no. 1, pp. 290-296, 2010.

[28] E. Vittinghoff and C. E. McCulloch, "Relaxing the rule of ten events per variable in logistic and cox regression," American Journal of Epidemiology, vol. 165, no. 6, pp. 710-718, 2007.

[29] L. B. Meuleners, A. H. Lee, and C. Haworth, "Road environment, crash type and hospitalisation of bicyclists and motorcyclists presented to emergency departments in Western Australia," Accident Analysis and Prevention, vol. 39, no. 6, pp. 1222-1225, 2007

[30] S. M. Rifaat, R. Tay, and A. de Barros, "Effect of street pattern on the severity of crashes involving vulnerable road users," Accident Analysis and Prevention, vol. 43, no. 1, pp. 276-283, 2011.

[31] E. Dumbaugh and W. Li, "Designing for the safety of pedestrians, cyclists, and motorists in urban environments," Journal of the American Planning Association, vol. 77, no. 1, pp. 69-88, 2011.

[32] E. Heinen, B. van Wee, and K. Maat, "Commuting by bicycle: an overview of the literature," Transport Reviews, vol. 30, no. 1, pp. 59-96, 2010.

[33] C. C. O. Reynolds, M. A. Harris, K. Teschke, P. A. Cripton, and M. Winters, "The impact of transportation infrastructure on bicycling injuries and crashes: a review of the literature," 
Environmental Health: A Global Access Science Source, vol. 8, no. 1 , article 47, 2009.

[34] A. C. Lusk, P. G. Furth, P. Morency, L. F. Miranda-Moreno, W. C. Willett, and J. T. Dennerlein, "Risk of injury for bicycling on cycle tracks versus in the street," Injury Prevention, vol. 17, no. 2, pp. 131-135, 2011.

[35] J. K. Kim, S. Kim, G. F. Ulfarsson, and L. A. Porrello, "Bicyclist injury severities in bicycle-motor vehicle accidents," Accident Analysis and Prevention, vol. 39, no. 2, pp. 238-251, 2007.

[36] P. O. Wanvik, "Effects of road lighting: an analysis based on Dutch accident statistics 1987-2006," Accident Analysis and Prevention, vol. 41, no. 1, pp. 123-128, 2009.

[37] R. Bhatia and M. Wier, "'Safety in Numbers' re-examined: can we make valid or practical inferences from available evidence?" Accident Analysis and Prevention, vol. 43, no. 1, pp. 235-240, 2011.

[38] P. L. Jacobsen, "Safety in numbers: more walkers and bicyclists, safer walking and bicycling," Injury Prevention, vol. 9, no. 3, pp. 205-209, 2003. 


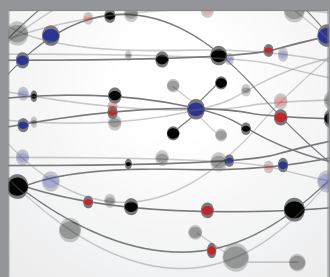

The Scientific World Journal
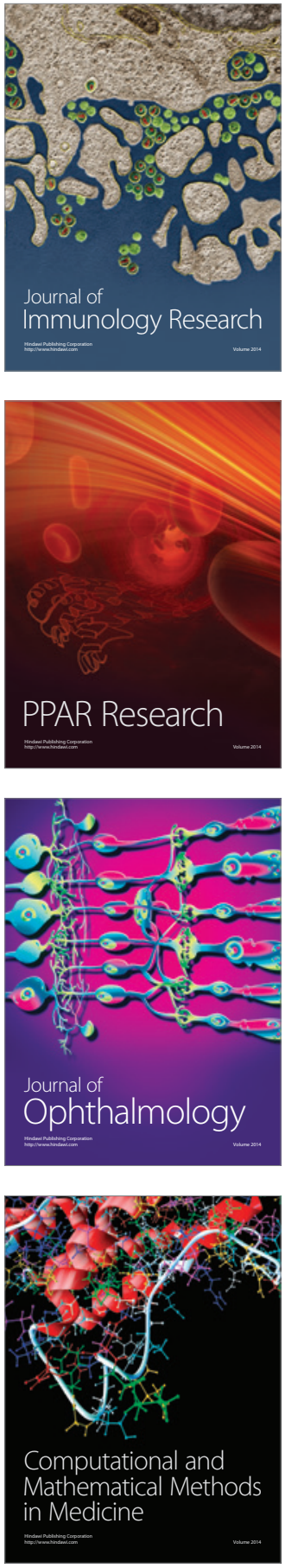

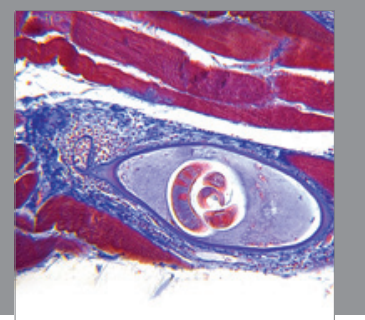

Gastroenterology

Research and Practice
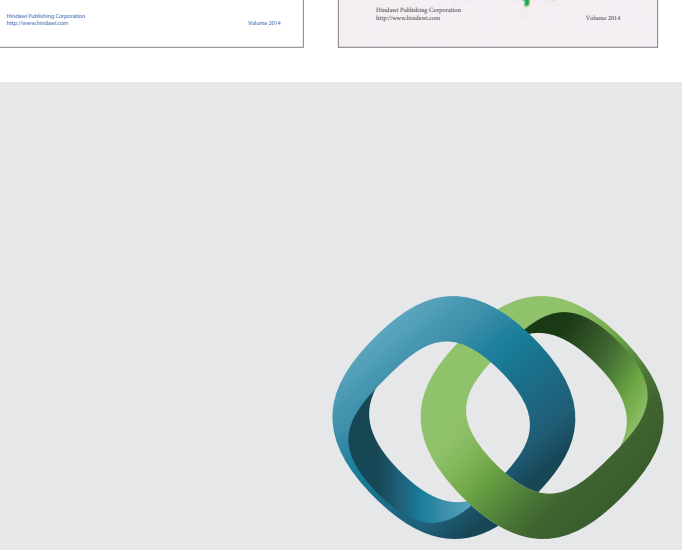

\section{Hindawi}

Submit your manuscripts at

http://www.hindawi.com
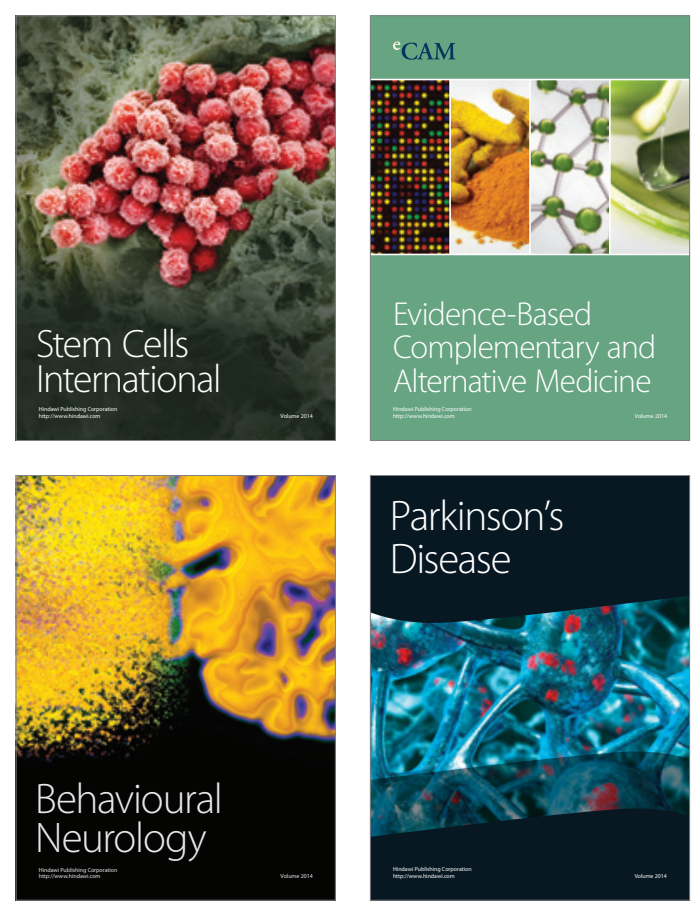

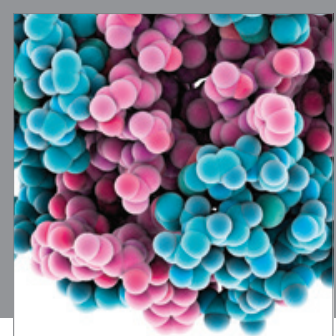

Journal of
Diabetes Research

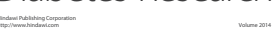

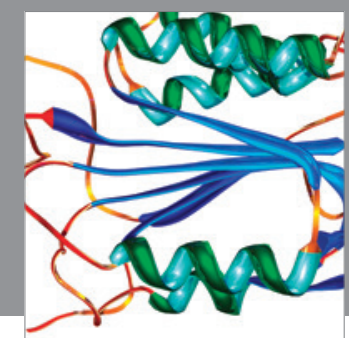

Disease Markers
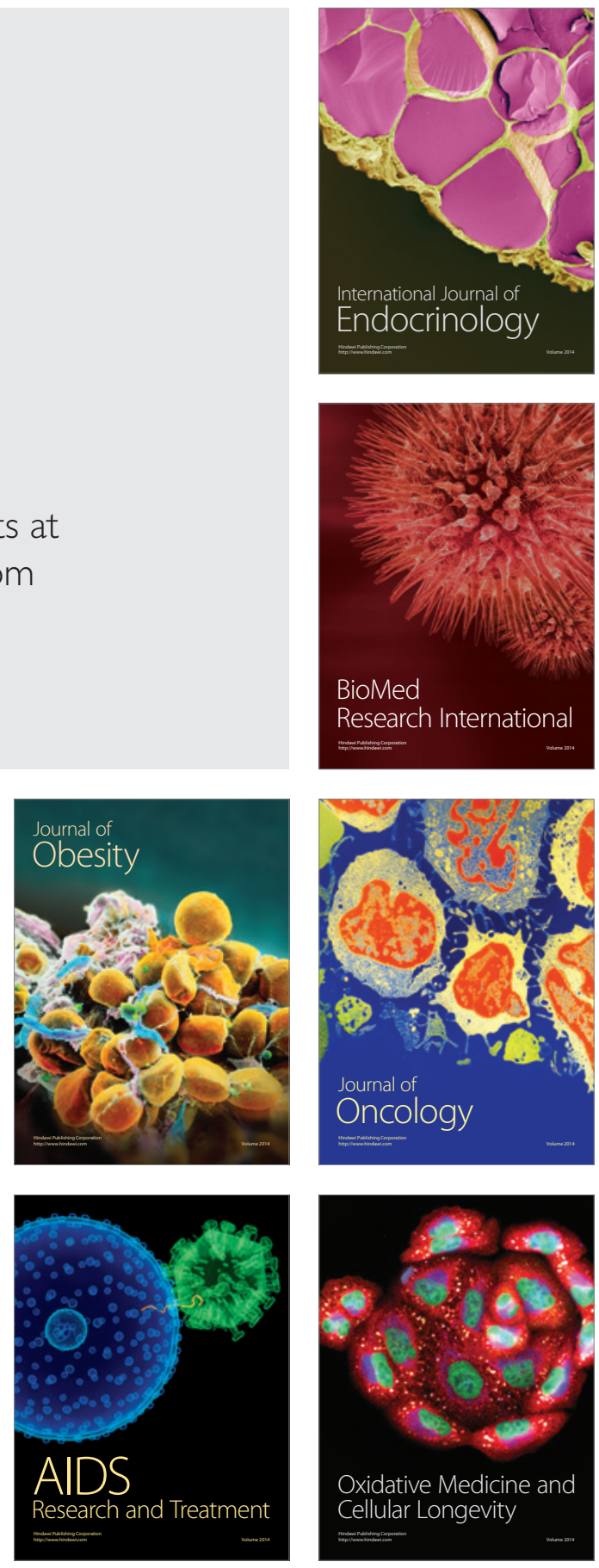